\title{
Two different volume of local anaesthetic in subarachnoid block for Minipercutaneous Nephrolithotomy in prone position
}

\author{
Shrestha BR ${ }^{1}$, Khadgi $S^{2}$, Shrestha $S^{2}$, Thapa $\mathbf{P}^{3}$
}

${ }^{1}$ Department of Anaesthesiology, Kathmandu Medical College, ${ }^{2}$ Endourologists, Venus International Hospital, Kathmandu, Nepal ${ }^{3}$ Public health specialist (MPH), Venus International Hospital, Kathmandu, Nepal

\section{Abstract}

Aims: To see the maximum sensory level in supine and prone position after subarachnoid block in patients undergoing Minipercutaneous Nephrolithotomy with two different volumes of local anaesthetic.

Methods: Prospective randomized comparative study in 500 patients undergoing Minipercutaneous Nephrolithotomy to find out the extensiveness of sensory level spread after spinal anaesthesia using two different volumes of local anaesthetic before and after keeping patients in prone position. Patients were divided into two groups: Group A (three ml hyperbaric Bupivacaine) and Group B (four ml hyperbaric Bupivacaine) consisted of 250 patients each. Spinal block was performed in sitting position. Sensory level and hemodynamic measurements were carried out at different time points while patients were on supine and on prone position.

Results: Patients attaining $T_{4}$ sensory level at five minutes in Group B was significantly higher than in Group $A(p=0.001)$. After 10-15 minutes of spinal block, greater number of patients in Group B reached $T_{4}$ sensory level while being in supine position than those in Group A and the difference was statistically significant $(p=0.000)$. After keeping the patients in prone position for in 10-15 minutes the number of patients reaching $\mathrm{T}_{4}$ level was found to be significantly higher in group A than in Group B $(p=0.063)$. Decrease in heart rate and blood pressure in prone position was significant from baseline value and while during supine $(p<0.05)$.

Conclusion: Prone positioning extends the sensory level of subarachnoid block to higher level $\left(\mathrm{T}_{4}\right)$ when three $\mathrm{ml}$ of hyperbaric solution is used.

Key words: Hyperbaric bupivacaine, mini-percutaneous nephrolithotomy, prone position, subarachnoid block

\section{Introduction}

urgery performed in prone position poses anaesthetic $\checkmark$ challenges in two ways: prone positioning either following general or regional anaesthesia brings about hemodynamic alterations due to reduction in cardiac index ${ }^{1}$ and control of air way may not be easy in prone position as compared to supine position. Meticulous and careful delivery of anaesthesia and vigilant monitoring during intraoperative period avoids this difficulty. Different kinds of surgery are performed in prone position under general anaesthesia with endotracheal intubation. In many centres Percutaneous Nephrolithotomy (PCNL)

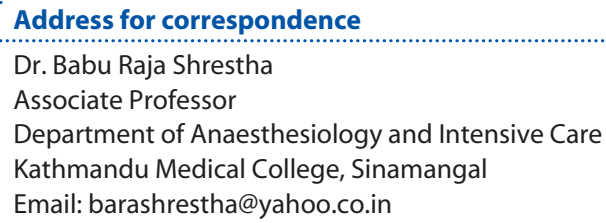

is performed under general anaesthesia. Surgeries are successfully carried out keeping patients prone following careful deliberation of spinal anaesthesia. This obviates the need of endotracheal intubation and avoids multiple drugs used in general anaesthesia. Patients are able to maintain their airway on their own as they remain awake and conversant during the procedure. The exact volume of local anaesthetic for spinal anaesthesia to patients going to be kept in prone position has not yet been clearly described elsewhere.

With the emergence of new techniques and skills, larger and even stag horn kidney stones have been fragmented and successfully evacuated by the method of Minipercutaneous Nephrolithotomy (MPCNL). This technique of minimal invasive endourological surgery is less aggressive and traumatic and even quicker in itself. 
PCNL with a 28-30 Fr tract size is an established method for renal stone removal ${ }^{2}$. Chinese method of MPCNL using 12-20 $\mathrm{Fr}$ tracts is improvised technique and is less invasive in comparison to $\mathrm{PCNL}^{3-4}$. Less stressful and minimally invasive type of surgery demands alike anesthetic techniques which enable more rapid recovery and safe discharge of patients. Anaesthesia can affect the early postoperative recovery of patients hence the choice of anaesthesia matters ${ }^{5}$.

\section{Objective}

1. To compare the sensory level attained by patients in two groups in supine position.

2. To compare the maximum sensory level achieved in supine and prone position between two groups.

\section{Methods}

This was a prospective randomized comparative study which was designed to find out the level of sensory block in patients after giving spinal anaesthesia in supine and prone position, using two different volume of local anaesthetic. After obtaining ethical clearance from the institutional research board and informed written consent from 500 patients of ASA (American Society of Anaesthesiologist) I and II undergoing MPCNL, the patients were randomly assigned using lottery method to two groups: Group A receiving three $\mathrm{ml}$ of hyperbaric bupivacaine and Group B receiving four $\mathrm{ml}$ of the same agent for subarachnoid block. The study was started on 15 March, 2010 and accomplished on September, 2010. The inclusion criteria were:

1. Patients of ASA I and II of age group 20-70 years.

2. Patients having body weight of $45-80 \mathrm{~kg}$.

3. Patients with minimum height of $150 \mathrm{~cm}$.

The following were the exclusion criteria adopted in the study:

1. Patients other than ASA I and II.

2. Patients with history of coagulopathy, ingestion of antiplatelet drugs and infection on their back at the site of lumbar puncture.

3. Patients with deformed spine.

4. Refusal for spinal anaesthesia

5. Ineffective or partial spinal block not reaching the desired sensory level of $T_{5-6}$ and needing general anaesthesia afterwards.

An hour prior to surgery all patients were premedicated with injection Ranitidine $50 \mathrm{mg}$ and Metoclopramide $10 \mathrm{mg}$ intravenously. Upon arrival to operation room venous access was secured and monitoring devices: non-invasive blood pressure, pulse oxymetry and electrocardiogram were applied to each patient and baseline hemodynamic values were recorded.

Spinal anaesthesia was performed in sitting position with full aseptic precautions using $27 \mathrm{G}$ Whitacre spinal needle at L3-4 intervertebral space. Patients were then kept in supine position. Hemodynamic parameters were recorded at different time intervals of 1, 3, 5 and 10 minute following spinal block while they were supine and first 10-15 minute of prone positioning. Sensory level was checked along the midaxillary line on both sides using ice-cube at the time interval of 5 and 10-15 minute while patients remained in supine position and at 10 minute following change of position to prone. To facilitate venous drainage and have abdomen free, two bolster rolls were kept at two different sites- one at the xiphisternum and other one at iliac crest level. The highest sensory levels achieved in supine position and at 10 minutes of prone positioning were recorded.

Heart rate less than 50/minute and mean arterial pressure (MAP) drop more than $30 \%$ of the baseline value were managed with anticholinergics and crystalloid/vasopressor (Mephentermine) respectively. Increased MAP $>30 \%$ of baseline injection was corrected with injection Esmolol.

No sedation was administered intraoperatively and all patients remained awake during the whole procedure. The end point of this study was the $10^{\text {th }}$ minute after turning patients to prone position and the sensory level achieved at this point of time was regarded as the highest level of sensory block in this study. Any adverse events if occurred during the procedure were noted and managed accordingly.

\section{Results}

The number of patients attaining the $T_{4}$ sensory level at 5 minute in Group B was significantly higher than in Group A ( $p=0.001$ ). After 10-15 minutes of spinal block total of 203 patients in Group B reached the $\mathrm{T}_{4}$ sensory level while being in supine which was higher than in Group A (26 patients) and the difference was statistically significant $(p=0.000)$. Comparing attainment of $T_{4}$ level in supine and after 10 minutes of prone position, more patients attained the level after 10 minutes of prone position as compared to supine position in Group A and the difference was statistically significant ( $p=0.001$ ). This relation did not hold consistent in Group B and the difference was not significant statistically $=0.066$. 
Shrestha BR et. al.

Table 1: Demographic characteristics of the participants

\begin{tabular}{lccc}
\hline Group & Sex, M:F & Age, years & Weight, kg \\
\hline A & $152: 98$ & $52 \pm 11.03$ & $58 \pm 17.04$ \\
B & $176: 74$ & $48 \pm 15.62$ & $54 \pm 10.62$ \\
p-value & & 0.16 & 0.11 \\
\hline
\end{tabular}

Table2: Sensory distribution

\begin{tabular}{|c|c|c|c|c|c|c|c|c|}
\hline \multirow[t]{2}{*}{ Group } & \multicolumn{2}{|c|}{$\begin{array}{l}\text { No. of patients having } \\
\text { sensory level at } 5 \text { minutes } \\
\text { in supine position }\end{array}$} & \multicolumn{2}{|c|}{$\begin{array}{l}\text { No. of patients with maximum } \\
\text { sensory level at } 10-15 \text { minutes in } \\
\text { supine position }\end{array}$} & \multicolumn{4}{|c|}{$\begin{array}{l}\text { No. of patients with maximum height of } \\
\text { sensory level after } 10 \text { minutes of prone } \\
\text { positioning }\end{array}$} \\
\hline & $\mathrm{T}_{6}$ & $\mathrm{~T}_{4}$ & $\mathrm{~T}_{5}$ & $\mathrm{~T}_{4}$ & & & $\mathrm{~T}_{3}$ & $\mathrm{~T}_{2}$ \\
\hline A & 232 & 18 & 224 & 26 & 238 & $p=0.001$ & 8 & 4 \\
\hline B & 101 & 149 & 47 & 203 & 233 & $p=0.066$ & 10 & 7 \\
\hline$p$-value & 0.005 & 0.001 & 0.000 & 0.000 & & & 0.096 & 0.099 \\
\hline
\end{tabular}

Table3: Heart rate per minute at different time points while in supine and in prone position

\begin{tabular}{lcccccc} 
Group & Baseline & $\begin{array}{c}\mathbf{1} \text { minute in } \\
\text { supine }\end{array}$ & $\begin{array}{c}\mathbf{3} \text { minute in } \\
\text { supine }\end{array}$ & $\begin{array}{c}\mathbf{5} \text { minute in } \\
\text { supine }\end{array}$ & $\begin{array}{c}\mathbf{1 0} \text { minute in } \\
\text { supine }\end{array}$ & $\begin{array}{c}\text { After } \mathbf{1 0}-\mathbf{1 5} \text { minute in } \\
\text { prone position }\end{array}$ \\
\hline A & $87 \pm 5.65$ & $76 \pm 4.00$ & $68 \pm 4.03$ & $61 \pm 6.00$ & $63 \pm 3.11$ & $62 \pm 5.02$ \\
B & $80 \pm 4.50$ & $72 \pm 5.9 .81$ & $67 \pm 2.31$ & $59 \pm 8.07$ & $51 \pm 3.09$ & $48 \pm 6.33$ \\
p-value & 0.077 & 0.061 & 0.510 & 0.067 & 0.032 & 0.027 \\
\hline
\end{tabular}

Table 4: Systolic blood pressure in $\mathrm{mm}$ of $\mathrm{Hg}$ in two groups

\begin{tabular}{lcccccc}
\hline Group & Baseline & $\begin{array}{c}\mathbf{1} \text { minute in } \\
\text { supine }\end{array}$ & $\begin{array}{c}\mathbf{3} \text { minutes in } \\
\text { supine }\end{array}$ & $\begin{array}{c}\mathbf{5} \text { minutes in } \\
\text { supine }\end{array}$ & $\begin{array}{c}\mathbf{1 0} \text { minutes in } \\
\text { supine }\end{array}$ & $\begin{array}{c}\text { After } \mathbf{1 0}-\mathbf{1 5} \\
\text { minutes in } \\
\text { prone position }\end{array}$ \\
\hline A & $138 \pm 11.09$ & $135 \pm 9.44$ & $125 \pm 13.28$ & $105 \pm 10.04$ & $95 \pm 14.81$ & $89 \pm 10.00$ \\
\hline B & $142 \pm 10.03$ & $138 \pm 7.11$ & $127 \pm 11.42$ & $100 \pm 15.53$ & $65 \pm 17.20$ & $56 \pm 8.04$ \\
\hline p-value & 0.086 & 0.090 & 0.10 & 0.088 & 0.020 & 0.001 \\
\hline
\end{tabular}

Table 5: Diastolic blood pressure in $\mathbf{m m}$ of $\mathrm{Hg}$ in two groups

\begin{tabular}{lcccccc}
\hline Group & Baseline & $\begin{array}{c}\mathbf{1} \text { minute in } \\
\text { supine }\end{array}$ & $\begin{array}{c}\mathbf{3} \text { minutes in } \\
\text { supine }\end{array}$ & $\begin{array}{c}\mathbf{5} \text { minutes in } \\
\text { supine }\end{array}$ & $\begin{array}{c}\mathbf{1 0} \text { minutes in } \\
\text { supine }\end{array}$ & $\begin{array}{c}\text { After } \mathbf{1 0}-\mathbf{1 5} \text { minutes in } \\
\text { prone position }\end{array}$ \\
\hline A & $71 \pm 6.90$ & $72 \pm 7.01$ & $68 \pm 6.97$ & $64 \pm 7.75$ & $60 \pm 3.32$ & $56 \pm 12.21$ \\
B & $69 \pm 4.00$ & $70 \pm 8.14$ & $67 \pm 4.33$ & $65 \pm 6.04$ & $54 \pm 9.07$ & $46 \pm 13.47$ \\
p-value & 0.071 & 0.067 & 0.213 & 0.286 & 0.061 & 0.040 \\
\hline
\end{tabular}

After keeping the patients in prone position in 10-15 minutes, the number of patients reaching $T_{4}$ level was found to be 238 from 26 in Group A whereas it was 233 in Group B which was not significant statistically ( $p=0.063)$. This shows that three $\mathrm{ml}$ of bupivacaine heavy in spinal anaesthesia is similar in effect to produce the same level of anaesthesia as does four $\mathrm{ml}$ of the drug once kept in prone position. There were patients in both groups who had exhibited maximum sensory level up to $T_{2-3}$, but the difference was not statistically significant $(p>0.05)$.

The decrease in heart rate was significant in Group B than in Group A after 10-15 minutes of spinal block while in supine position $(p=0.032)$ and the drop in heart rate was significant statistically in Group $B$ when patients were turned to prone position $(p=0.027)$. More 
of anticholinergics were used to correct the heart rate in group B.

The baseline and from first to fifth minute after spinal block systolic blood pressure was not found to be different statistically in two groups $<0.05$. The pressure decreased more in Group B at 10 minutes which further decreased following prone positioning in group $B$ and the decrease was highly significant statistically $(p=0.001)$.

Diastolic pressure in Group B significantly decreased as compared to the value in Group $A(p=0.040)$ in prone position. Other values for the pressure was not different in two groups while in supine position at different time points post subarachnoid block.

\section{Discussion}

This current study reveals that more number of patients receiving three $\mathrm{ml}$ of local anaesthetic in spinal block demonstrated cephalad migration of sensory block up to $\mathrm{T}_{4}$ after keeping them in prone position for 10 minutes while those receiving four $\mathrm{ml}$ of the drug exhibited sensory distribution up to the same level even in supine position. To put it another way three $\mathrm{ml}$ of bupivacaine heavy was found to be equally effective as of four $\mathrm{ml}$ of the drug in spinal anaesthesia to have the sensory level of $\mathrm{T}_{4}$ before commencement of MPCNL in prone position lasting for $55 \pm 37$ minutes, Table 2 .

Median age of patients in two groups was not different statistically $(p=0.16)$. Age difference may contribute in local anaesthetic distribution according to Cameron $\mathrm{AE}$ et $\mathrm{al}^{6}$ who state that the greater the age the more cephalad spread of the level of anaesthesia. The study was conducted in 33 patients aged 37-97 years with four $\mathrm{ml}$ of $0.5 \%$ hypobaric sugar free local anaesthetic. Comparable well controlled data on the spread of hyperbaric spinal anaesthetic solutions are not available.

The difference in weight in two groups was not significant statistically. Clinical experience indicates that obesity is of little direct clinical significance in determining spread of local anaesthetic solution in cerebrospinal fluid ${ }^{7}$. However, hyperbaric solution may be associated with unexpectedly greater cephalad spread because an obese patient will be in the slight head down position even though lying supine on an operating table that is horizontal.

Gender distribution in two study groups was similar in this study, having male patients predominant in each group. Sex of a patient has no direct effect on distribution of local anaesthetic solution in cerebrospinal fluid if all other factors involved in determining the distribution are kept constant ${ }^{8}$.

Difference in height of the patients must be fairly substantial if they are to have clinically significant effects on distribution of spinal block. The role of patients' height in determining sensory levels of spinal anaesthesia becomes clinically unimportant when spinal block is produced in children ${ }^{7,9}$.

Upper limit of height and its distribution was not taken into account in this study. Thus much could not be commented about the spread of local anaesthetic in terms of patients' height in our study which could be regarded as a weakness of the study.

The technique, site and speed of injection, size and direction of bevel of spinal needle were kept constant for all patients in both groups in the study. Barbotage was avoided in all cases. These factors could have effect on the local anaesthetic spread in cerebrospinal fluid ${ }^{10}$.

Dose $(\mathrm{mg})$ of local anaesthetic was found by Pflung et al to have no effect on its distribution in cerebrospinal fluid (CSF). Injection of $4.5 \mathrm{ml}$ of $0.5 \%$ Bupivacine $(22.5 \mathrm{mg}$ ) gave a level of anaesthesia no different than did injection of $3 \mathrm{ml}$ of $0.75 \%$ Bupivacaine $(22.5 \mathrm{mg})^{11-13}$. Injecting local anaesthetic into the intrathecal space causes bulk displacement of CSF away from the site of injection which depends greatly on baricity of the solution injected rather than the volume of the agent so long as position of the patient following spinal block is kept constant ${ }^{14}$. On the contrary, in our study, after giving four $\mathrm{ml}$ of local anaesthetic, sensory block was achieved up to $T_{4}$ sensory level after $10-15$ min in maximum number of patients than that produced by three $\mathrm{ml}$ of the same local anaesthetic in supine position. Change of position to prone caused more cephalad distribution of sensory level of anaesthesia in patients who got three $\mathrm{ml}$ of heavy Bupivacaine.

The local anaesthetic administered to intrathecal space gets fixed to its receptors ranging from 10 to 25 minutes after giving fixed maximum possible sensory height before regression of the block commences in due course of time $e^{15}$.

Our patients in this study were turned to prone position after 10-15 min span of time after ureteric catheterization for retrograde opacification of pelvicalyceal system during MPCNL. They were then kept in prone position with two transverse wedges one at xiphisternum and other one at iliac crest level to make abdomen free. The 
spread or restriction of local anaesthetic agent in prone position after intrathecal administration has not been well described yet in literatures.

The more cephalad spread of sensory anaesthesia in prone position that we observed in this study could have been possibly due to whirl motion of CSF during rotation of patients from supine to prone position with change of curvature of the spinal column and impedance to venous drainage from abdominal compartment causing epidural venous engorgement and relative upward shift of CSF. Interestingly this phenomenon was seen in group A whereas in Group B with higher volume of local anaesthetic the receptors might have been occupied earlier while already in supine position.

To perform MPCNL the sensory height attained with three $\mathrm{ml}$ of hyperbaric bupivacaine was more than sufficient for the patients going to be positioned prone after 10-15 min of supine position with acceptable haemodynamic changes than with four $\mathrm{ml}$ of the same agent for spinal anaesthesia which could produce higher sensory and thereby autonomic blockade leading to clinically significant bradycardia and hypotension: Table 3, 4, 5. The significant haemodynamic changes are further accentuated by the decreased cardiac index of prone position' ${ }^{1}$. There has been a finding that the physiologic impact of prone position on cardiorespiratory function is minor so long as the abdomen is not compressed ${ }^{16}$.

In our study there was more consumption of crystalloids, anticholinergics and vasopressors in patients of group $B$ to correct the resulting decreased heart rate and blood pressure.

Spinal anaesthesia is relatively easy to perform and allows the surgery to take place in the best possible conditions. There are certain possible risks of spinal anaesthesia for prone position surgery like potential for higher blocks, limited access to airway if patients are not fully awake, uncomfortable position for surgeries of long periods, need of repositioning if critical events occur and inconvenient if spinal anaesthesia does not work. Questions arise what in case of cardiac arrest. The patient can be turned supine on to the trolley. Literatures state that chest compressions in ${ }^{17,18}$. The prone position are possible and may generate higher systolic pressure and improve ventilation. Furthermore it is possible to defibrillate patients in the prone position with lateral pad positions ${ }^{19}$.

In this study none of the patients required repositioning or faced complications or failure of spinal blocks. The mean duration of surgery in this study was $55 \pm 37$ minutes which were well covered by the achieved height of $\mathrm{T}_{4}$ sensory level. In fact $\mathrm{T}_{8}-\mathrm{L}_{2}$ sensory level covers the kidney surgery. If surgery is allowed to proceed with this level regression of the block may cause pain sensation before the surgery is accomplished. The pulsatile pressurized irrigation through the endoscope during MPCNL with a pressure as high as $350 \mathrm{~mm}$ of $\mathrm{Hg}$ provides a clean view and allows flushing out of stone fragments ${ }^{20}$. On the other hand this much of pressure distends the calyceal system and stretches the tissues causing discomfort and pain to patients if sufficient sensory level is not achieved.

\section{Conclusion}

Three $\mathrm{ml}$ of injection Bupivacaine heavy in spinal block produces sensory block to $\mathrm{T}_{4}$ level after turning patients to prone from supine position within 10 minutes time as does four $\mathrm{ml}$ of the same drug. Thus three $\mathrm{ml}$ of Bupivacaine heavy for spinal anaesthesia is good enough for the surgery in prone position where the sensory level need not be more than $\mathrm{T}_{4}$ level.

\section{References}

1. Hatada $T$, Kusunoki $M$, Sakiyama $T$ et al. Hemodynamics in the prone jack-knife position during surgery. Am J Surg. 1991;162:55-8

2. Monga $M$, Oglevie S. Minipercutaneous nephrolithotomy. J Endourol. 2000;14:419-21.

3. Li X, Zeng GH, Liu JH et al. Minimally invasive percutaneous nephrolithotomy in the management of complex urinary calculi middle calyx puncture approach. Clin Urol. 2003;3:147-9.

4. Wong MY. Evolving technique of percutaneous nephrolithotomy in a developing country: Singapore General Hospital experience. J Endourol. 1998;12:397-401.

5. Rozentsveig V, Neulander EZ, Roussabrov E et al. Anesthetic considerations during percutaneous nephrolithotomy. J Clin Anesth. 2007;19:351-5.

6. Cameron AE, Arnold RW, Ghoris MW, Lamieson V. Spinal analgesia using bupivacaine $0.5 \%$ plain: variation in the extent of the block with patient age. Anesthesia. 1981;36:318-22.

7. Nicholas MG. Distribution of local anesthetic solutions within the subarachnoid space. Anesth Analog. 1985;64:715-30.

8. Brown DT, Wildsmith JAW, Covino BG, Scott DB. Effect of Baricity on spinal anesthesia with amethocaine. Br J Anesth. 1980;52:589-95. 
9. Axelsson $\mathrm{KH}$, Edstrom $\mathrm{HH}$, Widman GB. Spinal anesthesia with glucose-free $0.5 \%$ - bupivacaine: effects of different volumes. $\mathrm{Br} J$ Anesth. 1984;56:271-7.

10. Kitahara T, Kuri S, Yoshida J. The spread of drugs used for spinal anesthesia. Anesthesiology. 1956;17:205-8.

11. Bengtsson M, Malmqvist LA, Edstrom HH. Spinal analgesia with glucose-free bupivacaine: effects of volume and concentration. Acta Anesthesia Scand. 1984;28:583-6.

12. Chambers WA, Littlewood DG, Edstrom HH, Scott DB. Spinal anesthesia with hyperbaric bupivacaine: effects of concentration and volume administered. Br J Anesth. 1982;54:75.

13. Pfung A, Aasheim G, Beck H. Spinal anesthesia: bupivacaine versus tetracaine. Anesth Analog. 1976;55:489-92.

14. Smith TC. The lumbar spine and subarachnoid block. Anesthesiology. 1968;29:60-4.
15. David CW. Spinal anesthesia. Anesthesiology. 2001;94:888-906.

16. Archer DP, Ravussin P. Perioperative effects of the prone position: anesthesiologic aspects. Ann $\mathrm{Fr}$ Anesth Reanim. 1998;17:172-6.

17. Mazer SP, Weisfeldt M, Bai D, Cardinale C, Arora R, Ma C, Sciacca RR, Chong D, Rabbani LE. Reverse CPR: a pilot study of CPR in the prone position. Resuscitation. 2003 Jun;57(3):279-85.

18. Wei J, Tung D, Sue SH, Wu SV, Chuang YC, Chang CY. Cardiopulmonary resuscitation in prone position: a simplified method for outpatients. J Chin Med Assoc. 2006 May;69(5):202-6.

19. Walsh SJ, Bedi A, Miranda C. Successful defibrillation in the prone position. $\mathrm{Br} J$ Anesth. 2009 Sep;21(6):408-13.

20. Saltzman B, Khasidy LR, Smith AD. Measurement of renal pelvic pressures during endourological procedures. Urology. 1987;30:472-4. 